\title{
AHP- BASED SOCIAL VULNERABILITY INDEX FOR SMALL FISHERIES IN YUCATAN, MEXICO
}

\author{
Tatiana Merino-Benítez, Ileana Grave, Luis A. Bojórquez-Tapia
}

\begin{abstract}
We present here an implementation of the AHP for the development of a Social Vulnerability Index (SVI). Our approach addresses the inherent subjectivity of experts' judgements regarding the required pairwise comparisons. Using sensitivity analysis based on local partial derivatives, we identify the expert with the most sensitive pairwise comparison. In this way, it is possible to contrast the background and experience of the experts on the AHP's output. The results enable an understanding of individual expert's effect on the analysis that can be used to generate the best possible SVI. We illustrate the approach through the case study of household vulnerability of small fishing communities in Yucatan, Mexico.
\end{abstract}

Keywords: household, uncertainty, sensitivity analysis, pairwise comparisons

\section{Introduction}

Vulnerability is the state of people or places that are differentially affected by hazards. The response to hazards depends on a combination of socio-institutional and environmental drivers, as well as the society's adaptive capacity (Eakin et al., 2011). Therefore, vulnerability as a concept has been associated with multiple dimensions that imply high uncertainty in measurement and classification (Eakin and Bojórquez-Tapia, 2008). Typically, the quantification of vulnerability is achieved by modeling the susceptibility of social dimensions to hazards through the development of a social vulnerability index (SVI) (Tate, 2013). One widely used approach to SVI is Saaty's (1987) Analytic Hierarchy Process (AHP) to integrate the judgements of experts (Hadipour et al., 2020). Nevertheless, individuals involved in developing an AHP model usually have different viewpoints regarding the required pairwise comparisons to determine the relative importance of the decision criteria and alternatives. Therefore, one limitation of applying the AHP to SVI is the tacit assumption that the pairwise comparisons of the experts are equally valid, despite their different backgrounds and experience (Ivanco et al., 2017). We present here an implementation of sensitivity analysis to ascertain the effect of individual experts on AHPbased SVI. Results helped us to build consensus on the most appropriate AHP model for the study area.

\section{Objectives}

We show (1) the implementation of the AHP to identify the socio-institutional drivers that shape overall vulnerability of households of small fishing communities in Yucatan, Mexico; and (2) the application of sensitivity analysis to compare alternative AHP models and select the one that should be presented as the best possible SVI for the study region. 
ISAHP Article: AHP- based social vulnerability index for small fisheries in Yucatan, Mexico. To Be Submitted to the International Symposium of the Analytic Hierarchy Process 2020, Web Conference.

\section{Methodology}

We developed a four-level hierarchy to organize the economic, governmental and social drivers of socio-ecological change and the alternatives for adaptations (Figure 1). Four experts from different disciplines performed the respective pairwise comparisons, which were recorded independently. We thus obtained four sets of pairwise comparisons that expressed the viewpoints of political science (version 1), fisheries biology (version 2), coastal management (version 3), and environmental policy (version 4). We then implemented the sensitivity analysis approach proposed by Ivanco et al. (2017) to elicit the effect of each expert on the aggregated AHP. Accordingly, given the pairwise comparison matrices $C^{P_{j}} \in R^{\mathrm{m} \times \mathrm{m}}$ for each expert $\mathrm{P}_{\mathrm{j}}$, the aggregated group weight $\bar{G}_{r}^{(i, j-1) P} \sqrt{A_{r}^{1} A_{r}^{2} \ldots A_{r}^{P}}$ and its normalization $G_{r}^{(i, j-1)}=\bar{G}_{r}^{(i, j-1)} / \sum_{\mathrm{q}}^{m} \bar{G}_{q}^{(i, j-1)}$ were calculated in terms of the weight $A_{r}^{P_{j}}$ of the rth-criterion in level $i$, under the criterion $j_{i-1}$. The change on the normalized group weights, given by the variation of the element in the $k$ th row and $l$ th column, $a_{k l}$, in the pairwise comparison matrix, was obtained with the numerical approximation of the partial derivative $\frac{\partial G_{r}^{\left(i, j_{i-1}\right)}}{\partial a_{k \ell}}$ with the finite differences' method (Ivanco, 2015) for a perturbation value of $1 \%$ of each pairwise comparison. Next, we applied the interval judgement analysis proposed by Saaty and Vargas (1987) to determine the probability of rank reversals of the decision criteria of the aggregated AHP model.

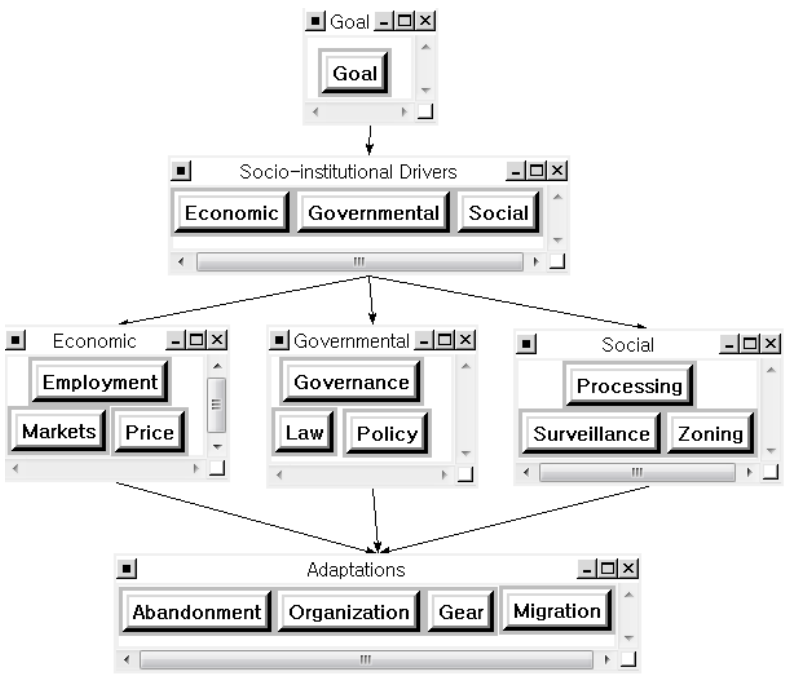

Figure 1. General structure of the AHP-based SVI

\section{Model Analysis}

The pairwise comparison matrices of criteria at the third hierarchical level showed marked differences between the experts (Table 1). The main differences were the following: for driver economic, the environmental policy expert judged price as more important than employment and markets; for driver governmental, the political science expert judged governance and law as less important than policy; for driver social, the fisheries biology expert judged processing and zoning as less important than surveillance. 
ISAHP Article: AHP- based social vulnerability index for small fisheries in Yucatan, Mexico. To Be Submitted to the International Symposium of the Analytic Hierarchy Process 2020, Web Conference.

Table 1. Pairwise comparison matrices of the third level of the AHP model from each expert

\begin{tabular}{|c|c|c|c|c|c|c|c|c|}
\hline \multirow{3}{*}{ Expert } & \multicolumn{8}{|c|}{ Driver } \\
\hline & \multicolumn{2}{|l|}{ Economic } & \multicolumn{3}{|c|}{ Governmental } & \multicolumn{3}{|c|}{ Social } \\
\hline & Employment & Markets & & Law & Policy & & Zoning & Surveillance \\
\hline \multirow{2}{*}{$\begin{array}{c}\text { Political } \\
\text { science }\end{array}$} & Price $\quad 1 / 2$ & 1 & Governance & 2 & $1 / 4$ & Processing & $1 / 3$ & 5 \\
\hline & Employment & 5 & Law & & $1 / 5$ & Zoning & & 6 \\
\hline \multirow{2}{*}{$\begin{array}{c}\text { Fisheries } \\
\text { biology }\end{array}$} & Price $\quad 1 / 5$ & $1 / 5$ & Governance & 1 & 5 & Processing & 2 & $1 / 2$ \\
\hline & Employment & 3 & Law & & 5 & Zoning & & $1 / 2$ \\
\hline \multirow{2}{*}{$\begin{array}{c}\text { Coastal } \\
\text { management }\end{array}$} & Price & $1 / 2$ & Governance & 4 & 3 & Processing & 3 & 3 \\
\hline & Employment & 4 & Law & & $1 / 3$ & Zoning & & 1 \\
\hline \multirow{2}{*}{$\begin{array}{c}\text { Environmental } \\
\text { policy }\end{array}$} & Price 7 & 9 & Governance & $1 / 6$ & 3 & Processing & 3 & 4 \\
\hline & Employment & 3 & Law & & 7 & Zoning & & 1 \\
\hline
\end{tabular}

Results of the sensitivity analysis showed that the environmental policy expert had the highest effect on the aggregated SVI model for drivers economic (0.45) and governmental $(0.40)$. For this reason, we generated two versions of the aggregated AHP model: model 1, including the four experts, and model 2, excluding the environmental policy expert.

The interval judgement matrices for these drivers (Table 2) were used as inputs to simulate 50,000 random matrices with random uniform numbers for each comparison. From the normalized weights of the consistent matrices $(\mathrm{CI}<0.1)$, results showed the possibility of rank reversals in two cases. For driver economic (Figure 2a-b), the histograms for the criteria showed clear differences between models 1 and 2: criterion price changed from the top to the bottom-ranking, whereas criterion employment changed from the middle to the top-ranking.

Table 2. Interval judgement matrices for the most sensitive criteria to the effect of the environmental policy expert

\begin{tabular}{|c|c|c|c|c|c|c|}
\hline \multirow{2}{*}{ Model } & \multicolumn{6}{|c|}{ Driver } \\
\hline & \multicolumn{3}{|c|}{ Economic } & \multicolumn{3}{|c|}{ Governmental } \\
\hline \multirow{3}{*}{1} & & Employment & Markets & & Law & Policy \\
\hline & Price & {$[1 / 5,7]$} & {$[1 / 5,9]$} & Governance & {$[1 / 6,4]$} & {$[1 / 4,5]$} \\
\hline & Employment & 1 & {$[3,5]$} & Law & 1 & {$[1 / 5,7]$} \\
\hline \multirow{3}{*}{2} & & Employment & Markets & & Law & Policy \\
\hline & Price & {$[1 / 5,1 / 2]$} & {$[1 / 5,1]$} & Governance & {$[1,4]$} & {$[1 / 4,5]$} \\
\hline & Employment & 1 & {$[3,5]$} & Law & 1 & {$[1 / 5,5]$} \\
\hline
\end{tabular}

The interval judgement analysis revealed the possibility of rank reversals in four cases (Figure 2). For driver economic, the rank reversal probability between price and employment was the highest (49\%) in model 1 and nil in model 2. In contrast, the rank reversal probability between price and markets was the highest (95\%) in model 2 and nil in model 1; the probabilities were negligible for the other cases. For driver governmental, the rank reversal probabilities between governance and law, and between law and policy

International Symposium on the Analytic Hierarchy Process
DEC. 3 - DEC. 6, 2020 
ISAHP Article: AHP- based social vulnerability index for small fisheries in Yucatan, Mexico. To Be Submitted to the International Symposium of the Analytic Hierarchy Process 2020, Web Conference.

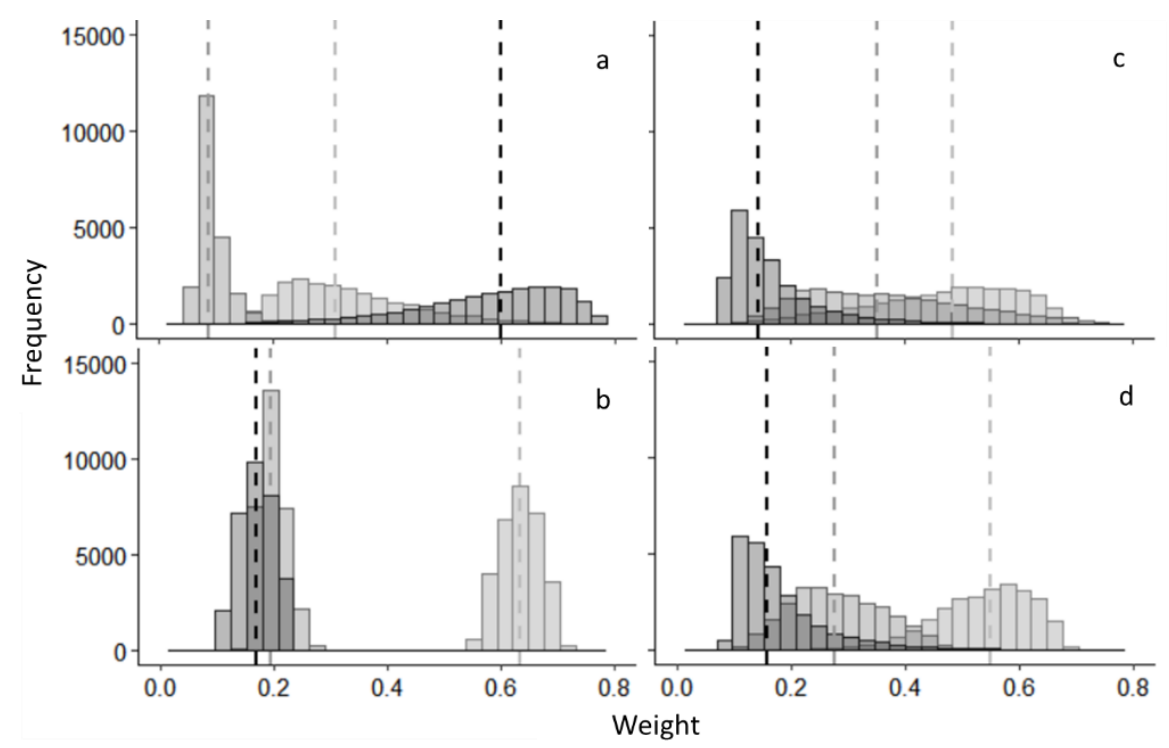

Figure 2. Results of interval judgement analysis for the criteria price (black), markets (grey), employment (light grey) of driver economic (left); and policy (black), law (grey), governance (light grey) of driver governmental (right); for models 1 (a and c) and 2 (b and d).

were the highest (50\%), and between governance and policy was the lowest (16\%) in model 1. In contrast, the rank reversal probability between law and policy was the highest (82\%) in model 2; the probabilities were negligible for the other cases.

The comparison of the global weights between models 1 and 2 (Figure 3) revealed that the four experts agreed on the relative relevance of adaptations migration and organization. Conversely, this comparison unveiled the disagreement between experts with regards of the relative importance of adaptation abandonment. The difference of the global weights of adaptations gear and abandonment was eight times smaller in model 1 than in model 2. Likewise, the global weights of adaptations gear, organization and abandonment ranged from 0.29 to 0.33 in model 1 .

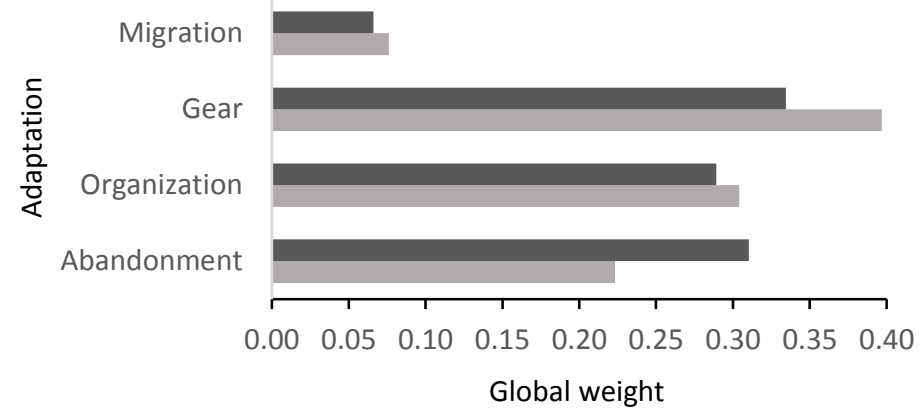

Figure 3. Global weights of adaptations for models 1 (black) and 2 (grey) 
ISAHP Article: AHP- based social vulnerability index for small fisheries in Yucatan, Mexico. To Be Submitted to the International Symposium of the Analytic Hierarchy Process 2020, Web Conference.

\section{Conclusions}

We demonstrated the importance of applying the AHP and sensitivity analysis to explore the contribution of each expert who participated in the construction of SVI for the assessment of the drivers and adaptations of small fishing communities. In our implementation, the exclusion of the environmental policy expert implied underestimating drivers price and law, and adaptation abandonment. Following a cautious strategy, experts judged that it was preferable to exaggerate rather than minimize the importance weight of abandonment as an adaptation. Accordingly, they selected model 1 as the basis of the SVI for the study region. The AHP together with the sensitivity analysis provided a rigorous and transparent means for building consensus amongst the experts on the best SVI between alternative AHP models.

Acknowledgements. This work was supported by UNAM PAPIIT-IV100118; ASUUNAM Binational Laboratory of Sustainability, Vulnerability, and Adaptation to Climate Change; FOMIX YUC-2018-04-01-88958. The first author acknowledges UNAM's Posgrado en Ciencias de la Sostenibilidad and the support of CONACYT 1003060.

\section{Key References}

Eakin, H. \& Bojórquez-Tapia, L. A. (2008). Insights into the composition of household vulnerability from multicriteria decision analysis. Global Environmental Change, 18, $112-$ 127.

Eakin, H., Bojórquez-Tapia, L. A., Monterde, R., Castellanos, E., \& Haggar, J. (2011). Adaptive Capacity and Social-Environmental Change: Theoretical and Operational Modeling of Smallholder Coffee Systems Response in Mesoamerican Pacific Rim. Environmental Management, 47(3), 352-367.

Hadipour, V., Vafaie, F., \& Kerle, N. (2020). An indicator-based approach to assess social vulnerability of coastal areas to sea-level rise and flooding: A case study of Bandar Abbas city, Iran. Ocean and Coastal Management, 188(105077), 1-16.

Ivanco, M.L. (2015). Development of analytical sensitivity analysis for AHP applications. [Master of Science thesis, Old Dominion University].

Ivanco, M., Hou, G., \& Michaeli, J. (2017). Sensitivity analysis method to address user disparities in the analytic hierarchy process. Expert Systems with Applications, 90, 111126.

Saaty, R. W. (1987). The Analytic Hierarchy Process-What it is and how it is used. Mathematical Modelling, 9(3), 161-176.

Saaty, T., \& Vargas, L. (1987). Uncertainty and rank order in the analytic hierarchy process. European Journal of Operational Research, 32, 107-117.

Tate, E. (2013). Uncertainty Analysis for a Social Vulnerability Index. Annals of the Association of American Geographers, 103(3), 526-543. 